\title{
The subchondral bone in articular cartilage repair: current problems in the surgical management
}

\author{
Andreas H. Gomoll • Henning Madry • \\ Gunnar Knutsen · Niek van Dijk · Romain Seil • \\ Mats Brittberg $\cdot$ Elizaveta Kon
}

Received: 8 January 2010/Accepted: 15 January 2010/Published online: 4 February 2010

(C) The Author(s) 2010. This article is published with open access at Springerlink.com

\begin{abstract}
As the understanding of interactions between articular cartilage and subchondral bone continues to evolve, increased attention is being directed at treatment options for the entire osteochondral unit, rather than focusing on the articular surface only. It is becoming apparent that without support from an intact subchondral bed, any treatment of the surface chondral lesion is likely to fail. This article reviews issues affecting the entire osteochondral unit, such as subchondral changes after marrow-stimulation techniques and meniscectomy or large osteochondral defects created by
\end{abstract}

Presented at the Conference, The subcondral bone in articular cartilage repair, October 8-10, 2009, Mondorf-les Bains,

Luxembourg.

This manuscript reviews emerging clinically relevant topics within the field of cartilage repair that Orthopedic Surgeons can consider integrating into their daily clinical practices.

A. H. Gomoll ( $\square)$

Department of Orthopaedic Surgery,

Brigham and Women's Hospital, Harvard Medical School, 850 Boylston St. Suite 112, Chestnut Hill, MA 02467, USA e-mail: agomoll@partners.org

\section{H. Madry}

Institute for Experimental Orthopaedics, Saarland University and Department of Orthopaedic Surgery,

Saarland University Medical Center,

Kirrberger Strasse, Building 37, 66421 Homburg, Germany

N. van Dijk

Department of Orthopaedic Surgery, Academic

Medical Center, University of Amsterdam,

Room G4-219, PO Box 22700, 1100 Amsterdam,

The Netherlands

G. Knutsen

Department of Orthopaedic Surgery, University of Troms $\emptyset$,

University Hospital North Norway, 9038 Troms $\emptyset$, Norway prosthetic resurfacing techniques. Also discussed are surgical techniques designed to address these issues, including the use of osteochondral allografts, autologous bone grafting, next generation cell-based implants, as well as strategies after failed subchondral repair and problems specific to the ankle joint. Lastly, since this area remains in constant evolution, the requirements for prospective studies needed to evaluate these emerging technologies will be reviewed.

Keywords Cartilage repair - Autologous chondrocyte implantation - Microfracture - Subchondral bone

\section{Introduction}

Articular defects can be limited to the superficial layer of cartilage or can extend deeper, also affecting the underlying

\section{R. Seil}

Service de Chirurgie Orthopédique, Centre de L' Appareil

Locomoteur de Médecine du Sport et de Prévention,

Centre Hospitalier de Luxembourg-Clinique d'Eich 78, rue d'Eich, 1460 Luxembourg, Luxembourg

\section{Brittberg}

Department of Orthopaedics, Kungsbacka Hospital,

Cartilage Research Unit, University of Gothenburg,

43480 Kungsbacka, Sweden

\section{E. Kon}

Laboratorio di Biomeccanica, Istituti Ortopedici Rizzoli,

Via Di Barbiano, 1/10, 40136 Bologna, Italy 
subchondral bone. Certain defects, such as those resulting from osteochondritis dissecans (OCD), may in fact start in the subchondral bone, only secondarily affecting the overlying cartilage. Other joint pathologies involving the subchondral bone include osteonecrosis and osteochondral fractures. There has been increased awareness that the subchondral bone plays an important role even in superficial lesions limited to the articular cartilage layer, since even focal chondral defects, if left untreated, may increase in size over time and result in concomitant changes in the underlying subchondral bone plate; either overgrowth or bone loss.

Recently, there has been an increasing interest and awareness of the importance of the subchondral bone for its role in the pathogenic processes, as well as the necessity to carefully consider this structure in the treatment of articular surface damage, in the evaluation of the results over time, and in the determination of the patients' prognosis. In fact, the conditions of articular cartilage and its supporting bone are tightly coupled and should be viewed as a connected osteochondral unit. The biomechanical alterations caused by (osteo)-chondral defects affect the articular cartilage surrounding and opposing the lesion, as well as the homeostatic balance of the entire joint. As such, there is increased likelihood for clinical progression to more widespread joint degeneration through mechanical disruption of joint motion, loose body formation, mechanical wear in the involved compartment, and attrition of opposing surfaces. This progressive decline may lead to degenerative joint disease with earlier onset of osteoarthritis. Therefore, the treatment goal for large chondral or osteochondral defects should be to restore the physiological properties of the entire osteochondral unit, aiming to achieve a more predictable repair tissue that closely resembles native articular surface and remains durable over time.

Marrow-stimulating techniques, osteochondral allografts or autografts, autologous chondrocyte implantation, scaffolds, and focal knee resurfacing implants are some of the main approaches proposed for the treatment of chondral and osteochondral lesions of the knee and the ankle. This article will discuss treatment options focusing on problems in the surgical management of the entire osteochondral unit and analyzing their effects on the subchondral bone structure.

\section{Subchondral bone changes after marrow-stimulating techniques}

Various techniques have been developed to repair fullthickness cartilage defects, chiefly among them marrowstimulation techniques (MST), such as subchondral drilling [64], abrasion arthroplasty [35], and microfracture [72].
MST attempt to stimulate filling of a cartilage defect with reparative tissue resulting from perforation of the subchondral bone. Blood and mesenchymal cells from the underlying marrow cavity form a clot in the defect that gradually differentiates into a fibrocartilaginous repair tissue [72]. MST procedures, in particular the more recently introduced microfracture technique, are generally considered as first-line treatment for full-thickness cartilage lesions and have demonstrated good to excellent results in $60-80 \%$ of patients $[55,71]$. There are, however, concerns over the durability of the repair tissue and hence the clinical outcome, especially in defects that are larger than 2$4 \mathrm{~cm}^{2}$ and located in areas other than the femoral condyles [28, 39, 42].

MST have been called "non-bridge-burning" procedures due to the belief that they would not negatively influence subsequent cartilage repair procedures such as ACI. Recent studies have demonstrated subchondral changes in up to one-third of patients treated with microfracture, such as thickening of the subchondral bone, and formation of subchondral cysts and intralesional osteophytes $[42,55]$. The findings are similar to those seen in chronic defects, which have yielded lower success rates after any type of cartilage repair, including ACI [26]. This has prompted concerns that treatment with MST could negatively impact later cartilage repair procedures.

As the understanding of the underlying pathophysiology grows, cartilage defects and osteoarthritis have become a disease of the entire osteochondral unit, rather than a disorder limited to surface cartilage alone [9]. One theory suggests activation of secondary centers of ossification in the subchondral plate as the initiating event in osteoarthritis [13]. While the entire osteochondral unit remains the same thickness, the tidemark advances with corresponding thinning of the overlying cartilage. This thinner layer of viscoelastic cartilage overlies a thickened and stiffened subchondral plate and is therefore more susceptible to damage from shear forces [4]. A similar mechanism can be postulated to occur after marrow-stimulation procedures: several studies have demonstrated a 27-33\% incidence of thickening of the subchondral plate and intralesional osteophytes [42, 55] (Figs. 1, 2). While there is conflicting evidence on the effects of previous marrow-stimulation on subsequent cartilage repair procedures [52, 53], these changes are regarded as a potential explanation for the deterioration and failure of microfracture [21, 65, 70]. It can be theorized that the altered subchondral plate is responsible for the worse outcomes both in chronic defects as well as in cartilage defects previously treated with marrow-stimulation techniques, where one study showed a failure rate of ACI in previously marrow-stimulated defects three times higher than in not previously treated defects [53]. 


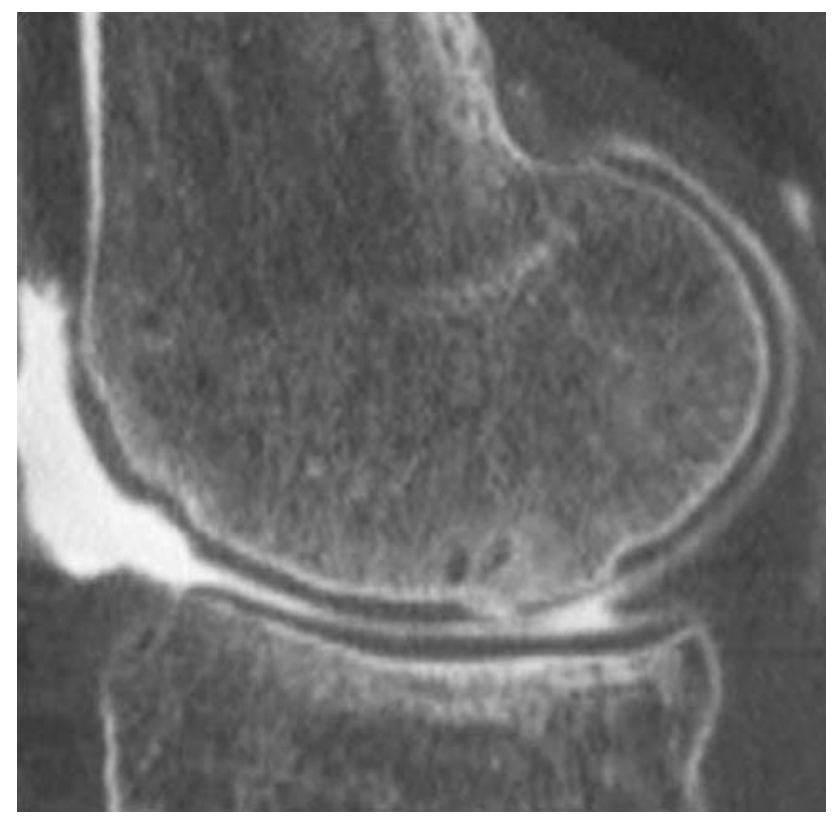

Fig. 1 CT arthrogram: sagittal view of a previously microfractured defect with a large intralesional osteophyte with very thin surface layer of fibrocartilaginous repair tissue

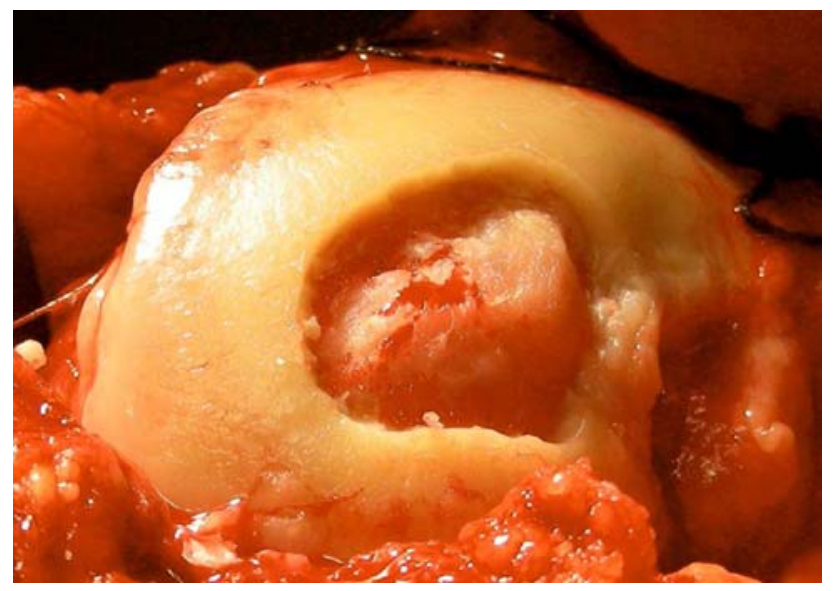

Fig. 2 Intra-operative image depicting the intralesional osteophyte shown in Fig. 1 after debridement of soft tissue coverage

\section{Bone allografts for subchondral lesions}

Osteochondral allograft transplantation has been used in Orthopedic Surgery for over 20 years to reconstruct severe osteochondral defects resulting from trauma, malignancy, and developmental disorders. In current practice in the United States, osteochondral allografts have also become a common option for the treatment of comparatively milder cartilage abnormalities, primarily those also affecting the subchondral bone, such as osteochondritis dissecans (OCD). More recently, the indications for allograft have been broadened to include the revision of failed prior cartilage repair procedures, especially in the setting of altered subchondral bone, such as is seen in $30-50 \%$ of patients after marrow stimulation (microfracture, drilling, and abrasion arthroplasty) [55].

Osteochondral allografting allows replacement of the entire osteochondral unit (articular cartilage and subchondral bone), thus avoiding the potential negative effects of altered subchondral bone on cell-based therapy procedures such as autologous chondrocyte implantation (ACI). Increasingly, allografts are now also being used as the primary treatment in situations where other restorative procedures have demonstrated limited success, such as in the very large or uncontained defect, or in the older patient population. Initially, limited by the low number of suitable grafts, fresh allograft tissue is becoming increasingly available in the US due to improved harvesting and storage protocols; however, the supply is still outpaced by a rapidly increasing demand.

The typical candidate for osteochondral allografting presents with a large full-thickness chondral or osteochondral defect and has failed prior procedures, such as the repair of an unstable OCD lesion, microfracture, osteochondral autograft transfer, or ACI. Some lesions preclude the use of other cartilage repair procedures, either due to their large size, specific location, or associated deep osseous defects. Localized unipolar lesions larger than 3$4 \mathrm{~cm}^{2}$, preferably in the femoral condyles, provide for an optimal environment for osteochondral grafting. Trochlear lesions can be treated as well but are technically more challenging due to the more complex geometry of the articular surface; and for patellar lesions, this technique represents a salvage option that should be considered once all else has failed.

Co-morbidities that must be addressed either prior to or at the time of the osteochondral allografting procedure include malalignment, ligament deficiency, and meniscal insufficiency. Bipolar lesions present a relative contraindication and result in less predictable outcomes.

Two techniques are generally utilized for osteochondral allograft transplantation: the shell and the dowel techniques. For the shell technique, the surgeon removes a geometric area of cartilage and bone with a bur and fashions a matching graft by hand, which is then secured in the defect with screw fixation. Technically difficult, and therefore only rarely used, this technique is advantageous for unusually shaped defects, such as very oblong lesions, or defects situated very posteriorly in the femoral condyles, where a dowel technique is not possible. The dowel technique, used for the vast majority of patients, is an extension of the osteochondral autograft technique, but utilizing larger grafts of $15-30 \mathrm{~mm}$ diameter. The cartilage defect (Fig. 3a) is prepared with a cylindrical reamer (Fig. 3b). A size-matched hemicondyle is ordered (Fig. 3c), and a dowel-shaped graft fashioned with the help of an allograft 
Fig. 3 a-e The dowel technique for the transplantation of an osteochondral autograft
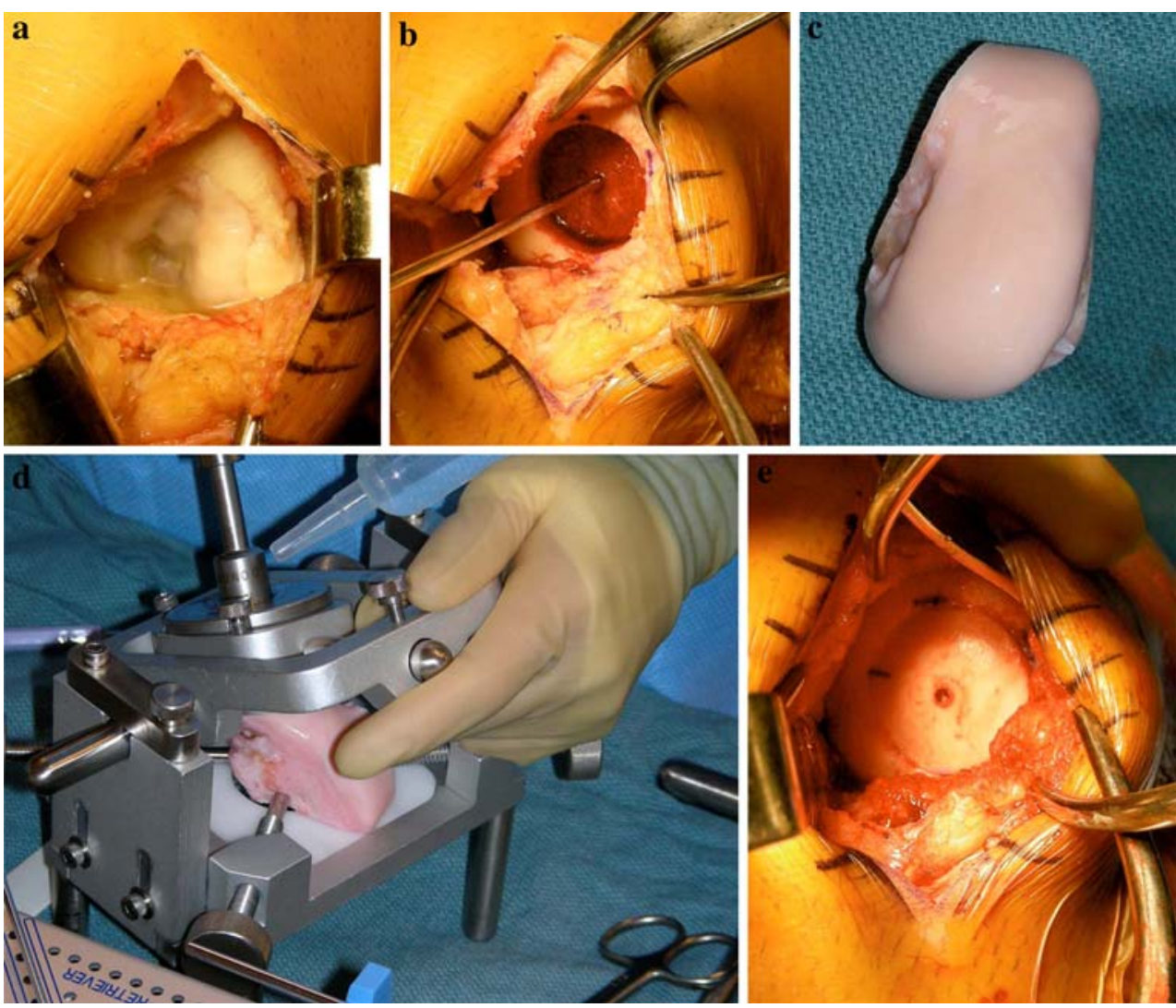

workstation (Fig. 3d). The graft is then secured in the recipient defect by press-fit fixation (Fig. 3e). Mid-term follow-up studies have demonstrated survival of more than $80 \%$ of grafts at $3-10$ years $[24,25]$.

Specific complications include the risk of disease transmission such as HIV or hepatitis, which is estimated at less than 1:150,000, as well as graft failure, usually at the subchondral level with delamination of the articular cartilage.

\section{Bone autografts for subchondral lesions}

Bone autografts are commonly used in general and sports orthopedics to encourage healing, for example after opening wedge osteotomies; and to address issues of bony deficiency, for example to address tunnel widening after failed ACL reconstruction. More recently, the use of bone autografts in the field of cartilage repair has increased to address similar issues, as will be discussed by using osteochondritis dissecans (OCD) lesions as an example. However, the same principles apply when treating any deep osteochondral defect, irrespective of its etiology and can also be considered when faced with substantially altered subchondral bone during the treatment of a cartilage lesion.

The preferred treatment for OCD lesions and osteochondral fractures is primary repair through osteosynthesis.
Chronic OCD lesions are frequently sclerotic, raising concerns over non-union with screw fixation alone. It has become accepted treatment to debride the bed of the lesion of all fibrous tissue and sclerotic bone to encourage healing. This can be enhanced further by adding bone autograft to the bed of the defect, which also assists in proper reduction in the fragment, which can otherwise be recessed too far into the defect, especially after thorough debridement of sclerotic margins. If the OCD lesion or osteochondral fracture cannot be repaired due to excessive fragmentation, reconstruction of the defect (Fig. 4a, b) can be performed with bone grafting and concomitant or staged cartilage repair.

Traditionally, iliac crest bone graft (ICBG) has been utilized as an excellent source for bone autograft; however, this harvest site is associated with substantial post-operative pain and morbidity. Therefore, alternative sources of bone graft have been investigated, such as allograft bone. While a viable source of structural graft, allograft bone does not provide living cells and is associated with increased cost. In our practice, the use of autograft bone from the proximal tibia or distal femur [57] has resulted in excellent outcomes with no additional cost, reduced morbidity by avoiding ICBG, and increased accessibility for knee operations, frequently through the same skin incision.

Most commonly, a cortical window is created over the medial surface of the proximal tibia or at Gerdy's tubercle 
Fig. 4 Large OCD lesion presenting after prior fragment removal: a arthroscopic and b open view
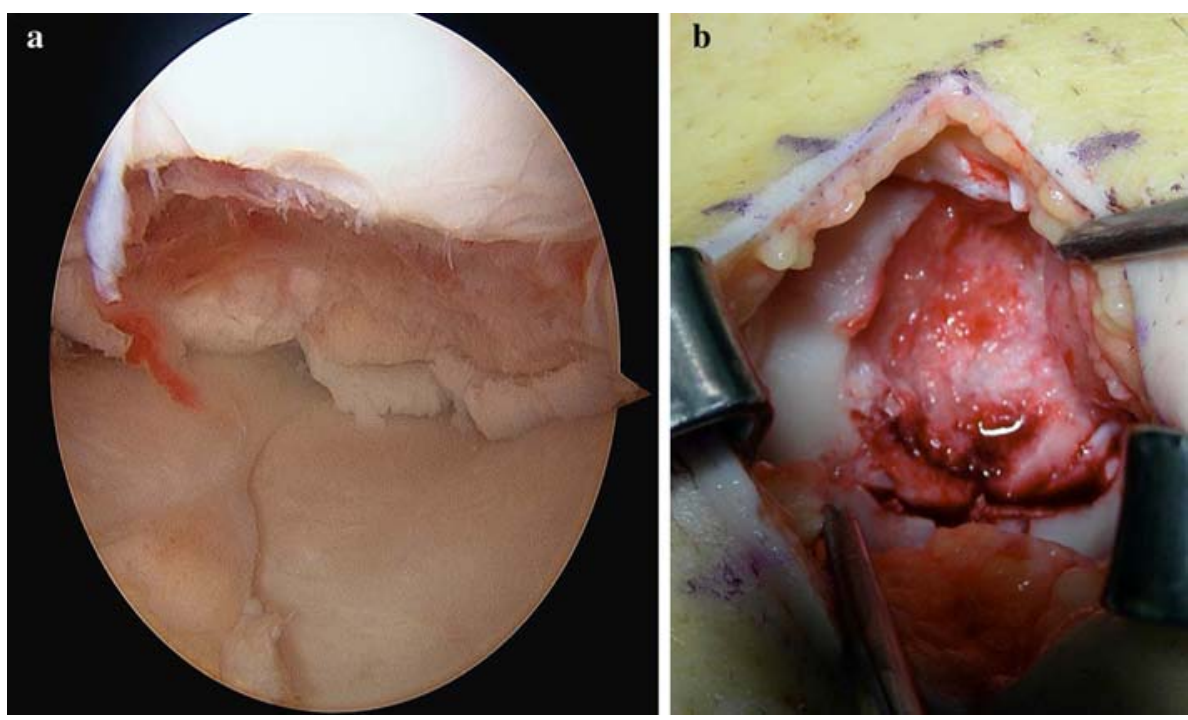

on the lateral aspect, depending on the location of the incision for the primary procedure. When harvesting bone graft for a high tibial osteotomy, a small incision can be made over the medial or lateral femoral epicondyle, protecting the insertions of the collateral ligaments, to obtain graft from the distal femur instead. A small window of approximately $1 \times 1 \mathrm{~cm}$ is created with an osteotome and removed. Any cancellous bone attached to the cortex can be harvested for graft material. A curette can now be used to harvest as much graft as needed to fill the defect. Alternatively, it has been helpful to utilize a 10-mm harvesting tube from any of the available osteochondral autograft transfer systems (Fig. 5). By aiming in different directions, at least 3-4 cores of cancellous bone measuring $10 \times 25 \mathrm{~mm}$ can be obtained, greatly improving ease and

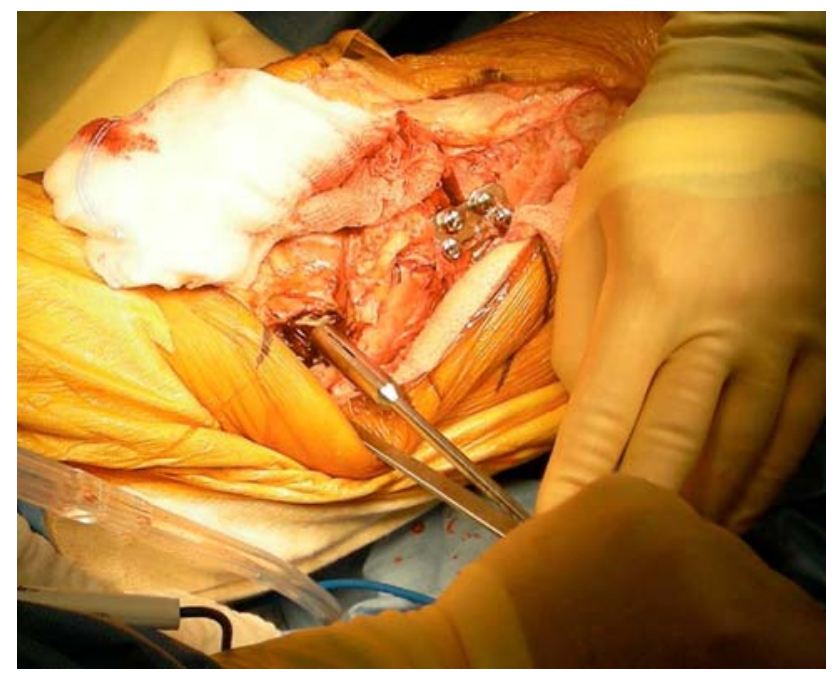

Fig. 5 Autogenous bone graft being harvested from the distal femur with a harvesting tube (different patient-here for grafting of an opening wedge high tibial osteotomy) length of graft harvest. The harvest site can then be filled with allograft chips or putty and the cortical window is replaced.

The graft material is now placed into the defect and compacted with a bone tamp (Fig. 6). The graft is then held in place with digital pressure and release the tourniquet, waiting for the resulting clot to solidify and stabilize the graft. For smaller defects, no additional fixation is required. In larger defects, a layer of fibrin glue is commonly added, with or without collagen membrane coverage, to secure the graft from displacement (Fig. 7). In cases of concurrent bone grafting and cartilage repair with cell-based therapy such as autologous chondrocyte implantation (ACI), a sandwich technique is used, applying the ACI on top of the membrane-covered bone graft. Lastly, for arthroscopic bone grafting techniques, the graft is morcellized and mixed with fibrin glue. Loaded into a syringe with the front end cut-off, the graft can be delivered into the defect and impacted with minimal spillage. Note, however, that this should be performed with the knee dry.

\section{Autologous chondrocyte implantation with scaffolds and the subchondral bone}

In the last 20 years, regenerative techniques, such as first and second generation autologous chondrocyte implantation, have emerged as a promising therapeutic option and several trials [11, 40] have confirmed the good clinical results of these treatments. Since being introduced in 1987 , the cell-based approach has gained increasing acceptance and recent studies highlight the long-term durable nature of this form of treatment due to the production of hyaline-like cartilage that is mechanically and functionally stable and integrates into the adjacent articular surface. 


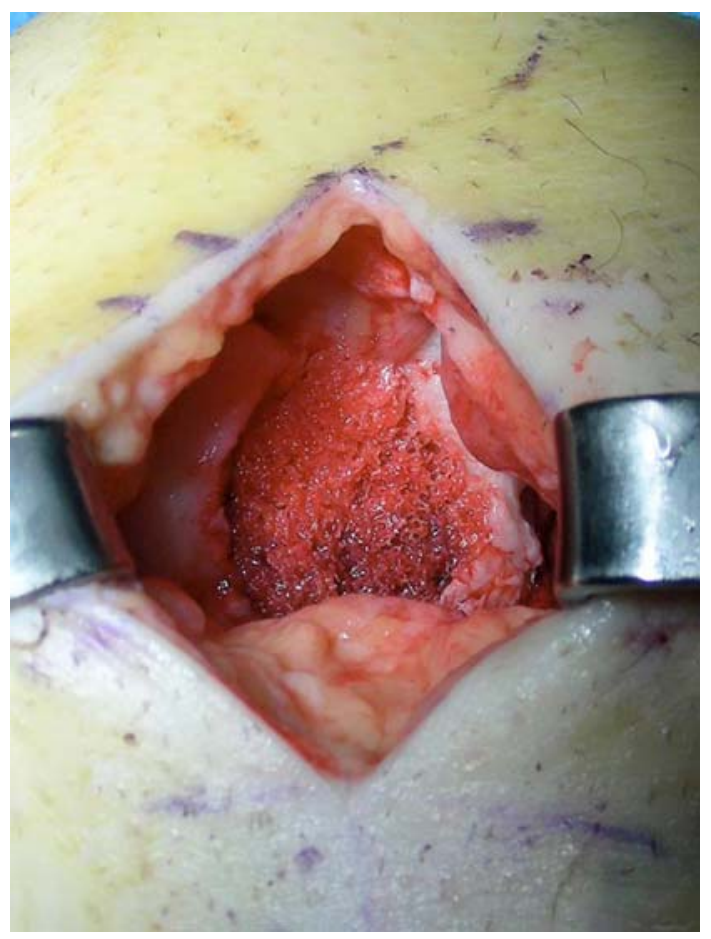

Fig. 6 The bone graft has been impacted into the defect

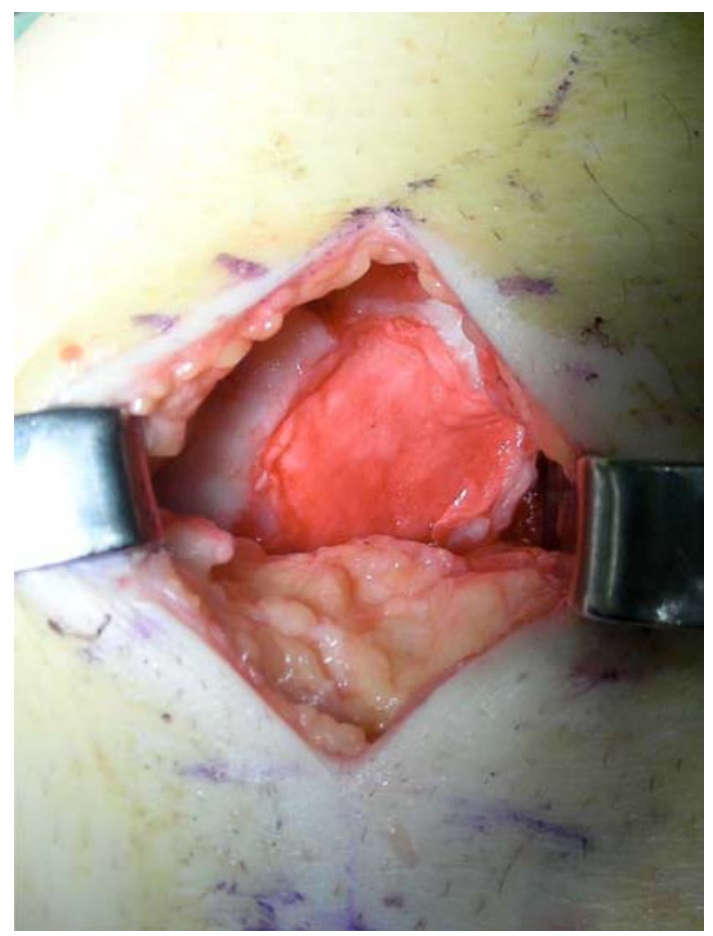

Fig. 7 The bone graft has been covered with fibrin glue and a collagen membrane for additional support

The recently developed second generation ACI techniques provide similar or superior results than the traditional ACI technique and simplify the procedure with marked advantages from a biological and surgical point of view [41]. This matrix-assisted chondrocyte implantation approach uses tissue-engineering technology to create a cartilage-like tissue in a three-dimensional culture system. Essentially, the concept is based on the use of biodegradable polymers as temporary scaffolds for the in vitro growth of living cells and their subsequent transplantation into the defect site.

The interpretation of subchondral bone changes present after autologous chondrocyte implantation as well as their correlation with the clinical outcomes is controversial. In general, bone marrow edema is associated with several diseases and is often observed in patients complaining of knee pain. Moreover, in patients with knee osteoarthritis, bone marrow edema lesions markedly increase the risk for structural progression of the condition, especially in the compartment affected by the bone marrow lesions [74]. Considering regenerative procedures, short-term results reported by some authors $[20,50]$ showed that the status of the subchondral bone was significantly correlated with clinical outcomes. Edema-like signal has been widely described early after ACI and has been attributed to graftimmaturity in the immediate post-operative period. Nevertheless, its interpretation remains controversial, and some authors see the persistence of edema-like signals for more than 1 year as a predictor for poor clinical outcome, while other studies regard edema as a sign of undetermined importance [27, 66].

In a recent MRI analysis of 40 patients treated for cartilage lesions with hyaluronan-based arthroscopic autologous chondrocyte implantation at minimum 5-year followup, the MRI evaluation showed subchondral bone changes (edema, granulation tissue, cysts, and sclerosis) in 50\% of the patients (data submitted for publication). Even though the total MOCART score was significantly correlated to the IKDC subjective evaluation, further analysis did not demonstrate a significant correlation of specific parameters, such subchondral edema, with clinical scores. However, the interpretation of such a high rate of subchondral bone changes after over 5 years was concerning, and the lack of correlation to the clinical outcome may have been due to the low number of patients analyzed. Therefore, all MRIs performed at different follow-up times and their respective clinical outcomes were analyzed together. The evaluation involved 78 knee MRIs, performed at least 24 months after second generation autologous chondrocyte implantation. The larger number of MRIs analyzed allowed increased power to detect any potential correlation between subchondral changes and clinical outcome, and indeed, the worst results were found in patients affected by bone marrow edema.

These findings demonstrate the importance of the subchondral bone and the need for further studies to better clarify its role in the pathologic processes, the importance 
of carefully considering this structure in the treatment of articular surface damage, in the evaluation of the results over time, and in the determination of the patients prognosis.

In particular, certain defects, such as those resulting from osteochondritis dissecans (OCD), osteonecrosis and more severe trauma are primarily osteochondral in nature with involvement of subchondral bone. In these patients, bone grafting and specific surgical procedures for articular surface reconstruction have been developed [63]. In fact, surgical treatment should always aim to re-establish the joint surface in the most anatomical way possible. However, most of the bioengineered tissues used in clinical practice were designed to promote healing of the cartilage layer only, but do not regenerate bone. Importantly, it must be considered that the subchondral bone may be involved not only in true osteochondral defects: even focal chondral defects, if left untreated, may increase in size over time and present concomitant changes of the underlying subchondral bone plate, either overgrowth or bone loss.

Articular cartilage and its supporting bone functional conditions are tightly coupled since injuries of either adversely affect the entire joint environment. The biomechanical perturbations caused by osteochondral alterations substantially alter pattern and magnitude of contact pressures and cartilage strains in the joint [69]. As such, they have the potential to contribute to the initiation and development of osteoarthritis. For this reason, several authors have highlighted the need for biphasic scaffolds, in order to reproduce the different biological and functional requirements for guiding the growth of the two tissues (bone and cartilage), to result in a predictable and durable repair. New scaffolds with osteochondral regenerative potential have been developed and evaluated with promising preliminary results. Niederauer et al. [59] investigated a multiphasic implant prototype using poly(D,L)lactide-coglycolide as the base material for the treatment of osteochondral defects in goats. Qualitative evaluations showed a high percentage of hyaline cartilage and good bony restoration, as well as tissue integration with the native cartilage. Moreover, no difference in healing was found between seeded and empty scaffolds. Jiang et al. [34] developed a biphasic cylindrical porous plug of poly(D,L)lactide-coglycolide, with the lower portion impregnated with B-tricalciumphosphate as the osseous phase. This composite construct was tested both cell-free and seeded with autologous chondrocytes, in the femoral condyles of mini-pigs, and good scaffold integration with cancellous bone formation in the implant periphery was found. In the chondral phase, hyaline cartilage regeneration was found in cellseeded group, whereas only fibrous tissue formed in the control group. Nagura et al. [58] developed a PLG bioabsorbable porous scaffold and tested it on full-thickness osteochondral defects in rabbit. Scaffold absorption with regeneration of the osteochondral defect was noted. They supposed that pore size may play an important role for both restoration and remodeling of cartilage and bone and degradation of PLG scaffold. Schlichting et al. [68] reported osteochondral defect healing using a polylactide-co-glycolide copolymer with calcium sulfate scaffold in two groups of sheep. One group was treated with a stiff scaffold, the other with a modified softer scaffold. Better healing of osteochondral defects was observed with the stiff scaffold. Schagemann et al. [67] carried out a study on osteochondral repair with implantation of cell-loaded and cell-free alginate-gelatin biopolymer hydrogel in sheep. Defects after treatment with hydrogel plus autologous chondrocytes were restored with smooth, hyaline-like neo-cartilage and trabecular subchondral bone, whereas the cell-free gel treatment revealed slightly inferior regenerate morphology. However, despite all the pre-clinical studies reported, only one scaffold used for osteochondral regeneration is currently available for clinical application. This is a bilayer porous PLGA-calcium-sulfate biopolymer (TruFit, Smith \& Nephew). Although pre-clinical results appear promising, there are no controlled studies, and only case reports have shown favorable results after implantation of these osteochondral substitutes. MRI evaluation at 12 months demonstrated heterogeneous repair tissue and information on long-term durability is not available [54, 80]. More recently, Kon et al. utilized an osteochondral nanostructured biomimetic scaffold with a porous 3D tri-layer composite structure in order to recreate the entire osteochondral anatomy. The cartilaginous layer, consisting of Type I collagen, has a smooth surface to favor joint motion. The intermediate layer (tide-mark-like) consists of a combination of Type I collagen (60\%) and HA (40\%), whereas the lower layer consists of a mineralized blend of Type I collagen $(30 \%)$ and HA $(70 \%)$ reproducing the sub-chondral bone layer. In vitro and animal studies showed good results in terms of both cartilage and bone tissue formation. Moreover, similar macroscopic, histological and radiographic results were observed when implanting scaffolds loaded with autologous chondrocytes or empty scaffolds, suggesting in situ regeneration through stem cells derived from the surrounding bone marrow [40]. Thus, this new osteochondral scaffold has been introduced into clinical practice as a cell-free approach with promising preliminary results.

\section{Subchondral bone defects after focal knee resurfacing implants}

The implantation of focal knee resurfacing implants (Fig. 8) is currently being advocated for the treatment of 


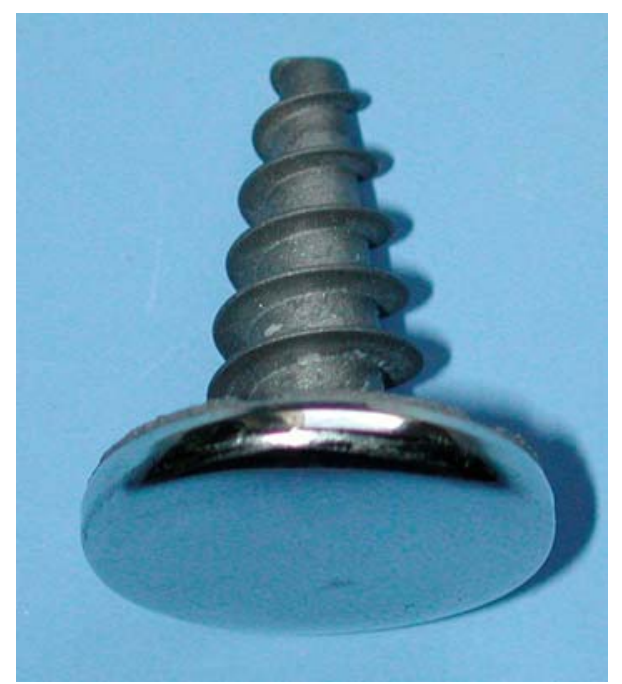

Fig. 8 HemiCap focal knee resurfacing implant after removal, showing the polished articular component and the porous-coated fixation component

full-thickness chondral and osteochondral defects as an alternative for marrow-stimulation techniques or osteochondral transplants. These implants consist of an articular component with a polished surface and a fixation component that connects the articular component with the epiphyseal bone. Suggested indications include defects caused by trauma, osteonecrosis, localized osteoarthritis and osteochondritis dissecans in patients older than 40 years [38]. These implants are characterized by good osseointegration [16, 38]. However, although such implants are already used in the treatment of localized cartilage defects in the knee, hip, shoulder and toe, little is known about their long-term properties and emerging experimental data serves to caution and to establish a clear indication for their use.

For example, Custers et al. [15] implanted metal implants with a $3.5-\mathrm{mm}$ diameter articulating surface in osteochondral defects in the medial femoral condyle in a rabbit model. After 4 weeks, cartilage degeneration was found in the opposing cartilaginous surfaces in the knees treated with metal implants. This cartilage degeneration caused by metal implants was significantly higher compared to microfractured or untreated defects. Tibial cartilage quality was least compromised when implants were placed flush compared to deep or protruding position [16]. When defect-size femoral implants were used for the treatment of osteochondral defects in the medial femoral condyle in a goat model, this treatment did not prevent cartilage degeneration in the articulating cartilage of the medial tibial plateau post-operatively compared with untreated, empty defects [17] or with defects treated by microfracture [17]. These experimental data suggest that caution is warranted using focal knee resurfacing implants as a treatment for established localized cartilage defects.

In the clinical setting, focal knee resurfacing implants have been advocated particularly for elderly patients as a less-invasive means of resurfacing focal articular cartilage defects. However, implantation in younger patients with good subchondral bone begets the question of how to treat the subsequent subchondral bone damage following a potential removal in the future (Fig. 9). Indications for implants removal include, for example, persistent pain, loosening or infection [31]. With sizes of the articular component often larger than $3 \mathrm{~cm}^{2}$, a deep osteochondral defect results that has to be treated, either by multiple osteochondral autografts or by autologous chondrocytes transplantation, the latter requiring concurrent or staged restoration of the subchondral bone with bone grafts.

Although focal knee resurfacing implants may be appropriate for elderly patients as a less-invasive option for resurfacing localized and deep osteochondral defects, it is important to avoid unnecessary destruction of the subchondral bone resulting from their implantation, particularly in young patients. Because of the potential problems that occur after removal of such implants, these implants should not be recommended for patients who are too young to undergo unicondylar or total knee arthroplasty as a revision option. In these patients, restoration of the damaged subchondral bone is preferred using a biological method. In conclusion, small focal knee resurfacing implants should not be used in young patients due to the potential difficulties in restoring the subchondral bone in case of implant removal.

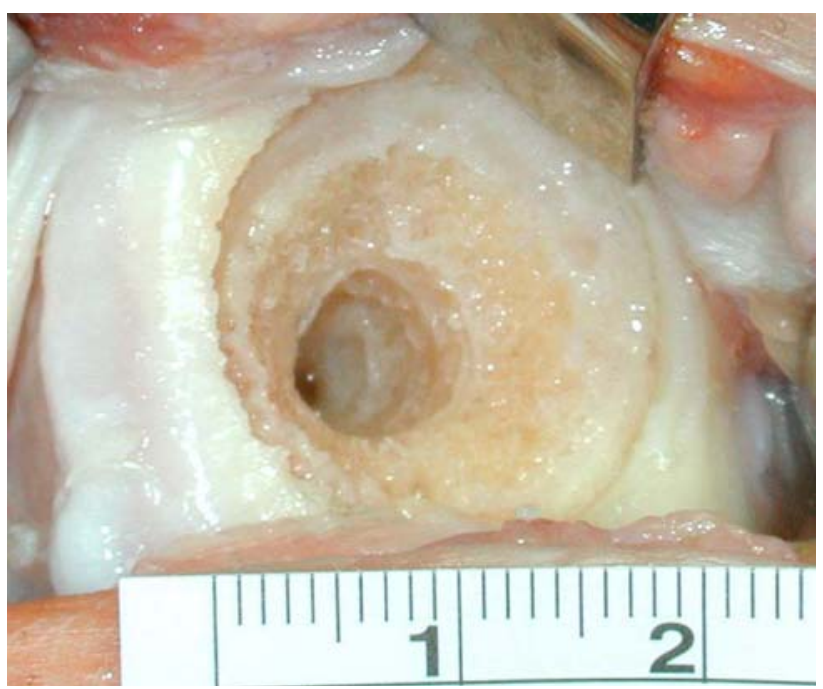

Fig. 9 Subchondral bone defect with comparatively normal-appearing subchondral bone after removal of a HemiCap focal knee resurfacing implant. Note the depth of the subchondral bone defect caused by the fixation component 


\section{Strategies after failed subchondral bone repair}

It is well-known that cartilage defects are difficult to repair. It is also known that changes in subchondral bone may alter the biomechanical properties of the subchondral plate and thus influence the long-term survival of the repair tissue after different cartilage repair methods. Healthy subchondral bone of lower elasticity is normally present to absorb much of the forces generated during impulse loading, protecting the cartilage layer [19]. Similarly after cartilage repair, the regenerative tissue needs support from healthy subchondral bone, otherwise the overlying cartilage repair will ultimately fail. This supporting bone should be strong and elastic yet deformable [19].

A large number of factors may limit proper bone healing. The early repair stage may be adversely altered by the administration of anti-inflammatory medications, immunosuppression, and steroids [3, 8, 22]. Vascularization of the bone tissue in the first few weeks could also be negatively influenced by nicotine $[18,77,85]$. The patient should stop smoking at least 3 weeks prior to surgery and, not resume until after the bone has healed. Radiation [82] and systemic diseases such as diabetes, rheumatoid arthritis, and osteoporosis are recognized inhibitors of successful bone healing and fusion [2, 14, 23]. The surgeon has to discuss such negative factors before a second surgery.

Furthermore, the proper amount of stress placed on a graft varies based on anatomical region and overall stability of the bone. Resorption may occur in areas where bone is not exposed to the right type of mechanical stresses [37]. Subsequently, one has to consider the weight-bearing characteristics of the patient; for example, whether there is too much varus or valgus malalignment. Should a concomitant unloading osteotomy be performed or is it enough to use an unloader brace just during the healing period? The choice of how to treat a failed subchondral repair depends on the previous method used and the size of the defect. Small to medium defects can be treated by implantation of autologous osteochondral plugs (Fig. 10) to address both the osseous and cartilaginous loss of tissue [29]. If the defect is deep, multiple purely osseous grafts from the surrounding bone can be harvested and implanted first, followed by implantation of osteochondral grafts on top (Fig. 11). Moderate to larger sized defects can be treated by autologous chondrocyte implantation using the sandwich technique (Fig. 12) $[10,36]$. The bony defect is filled with bone graft and periosteum or a collagen membrane is put on top of the bone graft level with the subchondral bone plate. An additional periosteal or collagen membrane is sutured on top of the cartilage defect, and the cells are implanted between the two membrane layers. The bone graft used can be either autologous bone, synthetic

\section{Shallow small osteochondral defect $(<8-10 \mathrm{~mm})$}

\section{Multiple Osteochondral Grafts}

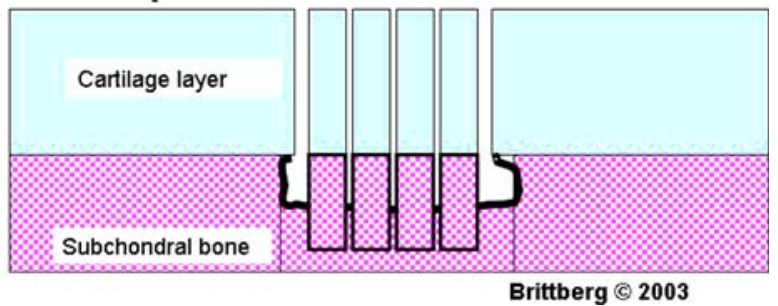

Fig. 10 Small to medium sized defects can be treated by standard implantation of autologous osteochondral plugs

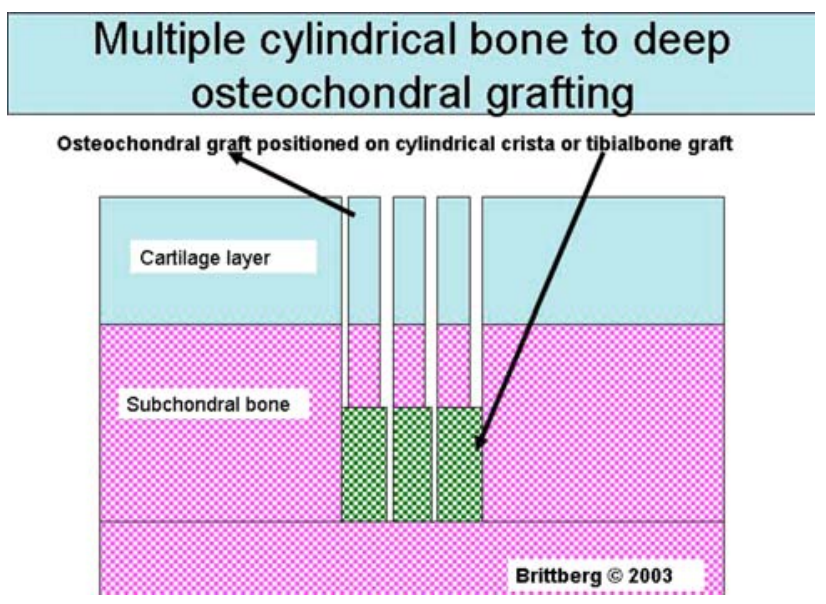

Fig. 11 If the defect is deep, multiple purely osseous grafts can be harvested from surrounding bone and implanted first into the base of the defect, followed by more superficial placement of the osteochondral grafts

bone, or a combination of both. It is important to tightly pack the bone graft by careful compression after marrow stimulation of the defect base to improve vascularization. The procedure can be performed arthroscopically with bone graft implanted via a tubular instrument (such as a syringe), followed by cartilage repair using a seeded membrane used in combination with fibrin glue; bone paste and chondral graft [10]. Very large osteochondral defects are treated by osteochondral allografts [43]. An autologous alternative is the transfer of the posterior aspect of the femoral condyle, the mega osteochondral transplantation (OATS) technology [12]. Finally, if the subchondral bone has failed but the overlying cartilage is still intact, such as in avascular necrosis or non-displaced OCD lesions, retrograde drilling and retrograde bone filling is an option. An ACL drill guide may then be used retrograde for the knee or a mini vector guide for the ankle to reach the insufficient bone area leaving the overlying cartilage intact. 


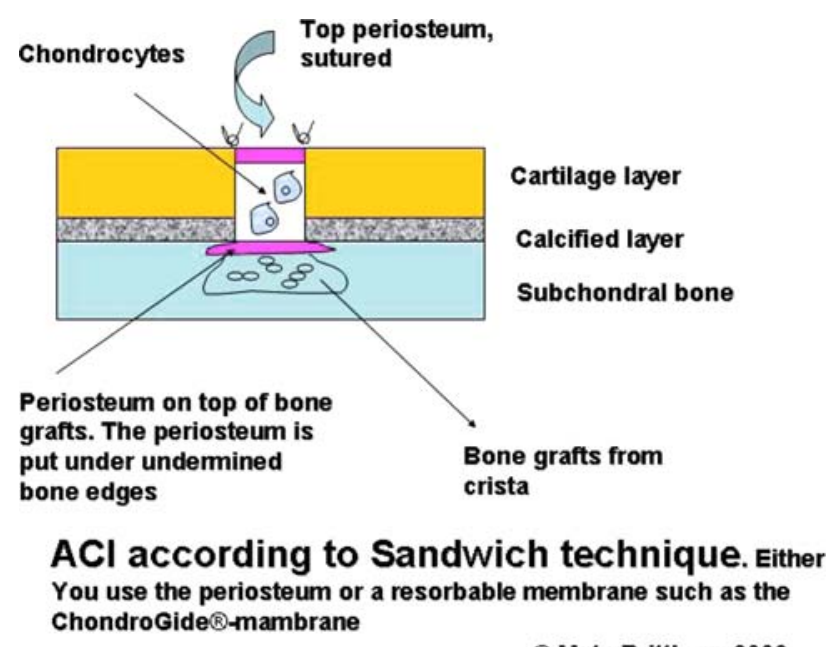

(c) Mats Brittberg 2003

Fig. 12 Moderate and deep defects can be treated by autologous chondrocyte implantation using the sandwich technique. Bone graft is packed into the base of the defect to reconstitute the bony defect, then covered by periosteum or a membrane. A periosteal flap or collagen membrane is then sutured to the surrounding cartilage according to standard ACI technique, and the cells are implanted between the two membranes

Growth factors and other drugs are also an option; several are available commercially and may be of interest when treating failed subchondral repair [79]. Biphosphonates have been reported to induce osteonecrosis in the mandible [44]. However, a bone graft can be treated with BMP-7 to increase new bone production and at the same time be protected against premature catabolism by a single dose of a bisphosphonate [30]. Local treatment of a bonegrafted area with bisphosphonate may diminish the risk of collapse during revascularization and bone remodeling in a mechanically loaded bone-grafted areas.

The role of subchondral bone in the pathogenesis of cartilage damage has likely been underestimated. Subchondral bone is not only an important shock absorber, but it may also be important for cartilage metabolism. When there are signs of insufficient subchondral repair, the surgeons has to consider revising not only the cartilage defect, but also address the subchondral bone changes. Careful pre-operative investigation and planning increases the chance for a successful outcome.

\section{Treatment strategies for osteochondral defects of the ankle}

Treatment strategies for osteochondral defects of the ankle have substantially increased over the last decade. Treatment of symptomatic chondral lesions include non-operative treatment with rest or casting, excision of the lesion, excision and debridement, excision combined with debridement and bone marrow stimulation (microfracturing), placement of cancellous bone graft, antegrade drilling, retrograde drilling, fixation of fragments, osteochondral autograft transplantation, autologous chondrocyte implantation (ACI), or limited prosthetic replacement. Goal of these treatments is to resolve symptoms and, ideally, to prevent the development of osteoarthritis in the long term. However, there are no long-term follow-up studies of untreated osteochondral defects that demonstrate progressive deterioration of the ankle joint. Reports of patients undergoing ankle replacement or ankle arthrodesis following OCD are rare. We therefore conclude that in the ankle joint, the natural history of a talar OCD lesion is mostly benign.

The reason for treatment is pain. Several factors might play a role. These include pain caused by rise in intraarticular pressure, rise in intraosseous pressure, synovial pain, or bone pain. Patients with localized OCD of the talus typically do not have joint effusion, and therefore it is unlikely that increased intra-articular pressure contributes to the pain. Patients with a talar OCD present with "deep ankle pain". The synovium of the anterior ankle joint is located directly under the skin and can easily be palpated. Patient with an OCD of the talus typically do not have recognizable tenderness on palpation of the synovium. Some patients have secondary synovial pain, which they can differentiate from the disabling deep ankle pain caused by the OCD. This deep ankle pain occurs during weight bearing and cannot be reproduced during physical examination. The nerve endings in the subchondral bone are the most probable cause of this pain [48]. Treatment strategies therefore have to concentrate on the subchondral bone rather than on the cartilage. Detection of the bone lesion is likewise more important than detecting the cartilage lesion itself. For detection of a talar osteochondral defect CT scan and MRI have shown similar accuracy [76]. A CT scan is the diagnostic strategy of choice. For pre-operative planning, CT scan is preferred since it demonstrates the exact size and location of the subchondral lesion. It is the subchondral lesion that has to be treated in order to treat the pain. The current preferred strategy for talar OCD is excision curettage and bone marrow stimulation [83]. Following excision and debridement of the lesion multiple connections with the subchondral bone are created by removing the calcified zone and perforating the subchondral plate. Intra-osseous blood vessels are disrupted and the release of growth factors leads to the formation of a fibrin clot. The formation of local new blood vessels is stimulated, bone marrow cells are introduced in the defect and fibrocartilage tissue is formed. The overall success rate has reported to be $85 \%$. 


\section{Subchondral bone changes associated with meniscal lesions}

Knee menisci are mobile fibrocartilaginous semilunar shock absorbers and load transmitters. They are fixed to the tibial plateau and to a lesser extent to the femur. A complete loss of the meniscus leads to an increase in tibiofemoral contact pressures and a significant decrease in the tibiofemoral contact areas [6, 61]. Peak contact stresses in the medial compartment increase proportionally to the amount of meniscus removed [45, 84], starting with as little as $20 \%$ of removed meniscal tissue [75]. As a consequence, knees without menisci are at great risk for the development of cartilage damage and osteoarthritis. Hence, maximum preservation of tissue should be the ultimate goal of any meniscal surgery.

Partial or total meniscectomy results in increased pressure on the articular cartilage. Finite element analysis revealed that both peak values and shear stress in the articular cartilage changed after meniscectomy, potentially leading to 2 types of cartilage damage [81]: Type 1 represents cartilage degeneration without disruption of the underlying bone or the calcified cartilage layer [5]. Type 2 represents a subchondral fracture with or without injury to the overlying cartilage [5] and might be a result of the measured $140 \%$ increase in shear stress at the articular cartilage—bone interface.

The biomechanical consequences of meniscal pathology on the underlying subchondral bone have been evaluated using quantitative CT or DXA measurements [47, 60, 62]. A close association between meniscal damage and increased subchondral bone mineral density in the tibial plateau of the corresponding tibiofemoral compartment has been found. In comparison with healthy knees, medial partial or total meniscectomy resulted in posteromedial displacement of the area of maximum density by approximately $4 \mathrm{~mm}$. These changes occurred within the first years after surgery and remained stable between 5- and 10year follow-up [60]. Similarly, an analysis of changes in trabecular bone strain in the proximal tibia as a result of partial and complete meniscectomy revealed altered load transfer from the articular surface through the trabecular region to the diaphysis [51]. As expected, the greatest change was seen in the subchondral region after complete meniscectomy. These bone changes indicate a relation between local bone density and bone marrow lesions [46]. Clinically, this might correlate with the commonly seen juxta-articular pain in patients in the early stages after partial or total meniscectomies.

The exact role of meniscal damage in the pathophysiology of osteoarthritis still remains to be determined [47]. It is highly prevalent in osteoarthritis [7], and recently it has been shown that these meniscal changes are predictive of structural progression of osteoarthritis [32]. One of the factors in need of further analysis is the inconsistency between the patterns of meniscal versus chondral damage in osteoarthritic patients [73]: it can frequently be observed that a segment of the meniscus, which was thought to experience an excessive load, was yet well preserved, or that cartilage lesions on the tibial plateau were located underneath an intact meniscus. These findings demonstrate that the exact interactions between the meniscus-cartilagesubchondral bone complex still largely remain unknown.

\section{Application of evidence-based medicine to the subchondral bone}

Evidence-based medicine has gained popularity in orthopedic surgery. Historically, surgeons have practiced what they learned from senior colleagues and then refined these techniques through their own experience and mistakes. It is also a fact that the majority of new techniques have been adopted in clinical practice without evidence from a randomized controlled trial [1]. Randomized controlled trials having enough power are difficult to perform in surgery. However, to move forward, randomized controlled trials are needed with long-term follow-up as an important supplement to registers and observational studies.

Fifty years ago, bone and subchondral bone were main targets in osteochondral repair. Bone grafting using autoand allografts has a long tradition in orthopedic surgery. For decades, subchondral bone was the main focus in cartilage repair. Scientists and surgeons believed that cartilage was impossible to regenerate in adults, and repair was initiated by debridement and drilling. Undoubtedly, progress has been made along the way, but in a sense we have closed the circle and are back to where we started. Many believed that cell-based therapies had solved the problem of repairing osteochondral defects. However, randomized controlled trials, clinical studies and meta-analyses have not given us the necessary evidence. A Cochrane review did not find evidence for superiority of any of the studied techniques for cartilage repair [78]. Another paper by Jakobsen et al. [33] concluded that the majority of studies on cartilage had a low methodological quality. Recently, another systematic review of the treatment of focal articular cartilage defects in the knee was published [49]. They identified five randomized controlled trials and concluded that no technique consistently had superior results compared with the others. A weakness of all studies was that no control (non-operative) groups were used. It is also fact that no technique available today has been able in clinical studies to prove the regeneration of normal hyaline cartilage. No doubt that tissue engineering has a great potential in osteochondral repair, and most of us realize that previous and current 
marrow-stimulation techniques are not the solutions for the future. However, new techniques have to be carefully evaluated before they are generally adopted.

Recently, subchondral bone again has come more into the spotlight again. Better understanding of the subchondral bone, and the interface and interaction between cartilage and the subchondral bone may help us solve some of these problems. This field of osteoarticular repair continues to evolve. New scaffolds are being introduced without thorough clinical evaluation. Companies sponsor testing of their own products in registries or even randomized controlled trials, injecting potential bias into these studies. Independent randomized controlled trials, registers and observational studies are needed to improve in this field. These principles also have to be applied to the new treatments aimed at repair of the subchondral bone. Randomized controlled trials are best suited for answering a therapeutic question, but they are difficult to perform and not always feasible. Randomized controlled trials and observational studies need to include enough patients, and therefore multi-center studies (national and international) having adequate power will be the future. Observational studies and even case series will still be useful by providing important information on natural history, prognostic factors, adverse treatment effects, and prevalence of certain diseases or outcomes [56].

\section{Conclusion}

The understanding of joint homeostasis and the interaction of cartilage and subchondral bone continues to evolve. After years of focusing almost exclusively on treating the easily accessible surface lesion, it is becoming apparent that without a healthy subchondral bed, the entire osteochondral unit is likely to fail. The future of cartilage repair lies in better diagnostics to properly recognize alterations in the subchondral bone that might compromise isolated cartilage repair, as well as advanced treatment options that will allow us to replace the entire osteochondral unit, should this become necessary. To this end, tissue-engineering techniques will be needed to generate a ready supply of osteochondral transplants that address the issues of limited autograft availability, as well as concerns over the use of allografts.

Acknowledgments We thank Elke Dooley for help with the manuscript preparation. Supported in part by the Deutsche Forschungsgemeinschaft (DFG) and the Fonds National de la Recherche (FNR).

Open Access This article is distributed under the terms of the Creative Commons Attribution Noncommercial License which permits any noncommercial use, distribution, and reproduction in any medium, provided the original author(s) and source are credited.

\section{References}

1. Ahn H, Bhandari M, Schemitsch EH (2009) An evidence-based approach to the adoption of new technology. J Bone Joint Surg Am 91(Suppl 3):95-98

2. Ahn IE, Ju JH, Park SH, Kim HY (2009) Radiologic observation: repair of focal bone erosions after humanized antitumor necrosis factor antibody adalimumab therapy in a patient with rheumatoid arthritis. Clin Rheumatol (e-pub ahead of print)

3. Anderson JM (2000) The cellular cascades for wound healing. In: Davis JE (ed) Bone engineering. Em Squared Inc, Toronto, pp 81-93

4. Armstrong CG (1986) An analysis of the stresses in a thin layer of articular cartilage in a synovial joint. Eng Med 15:55-61

5. Atkinson TS, Haut RC, Altiero NJ (1998) Impact-induced fissuring of articular cartilage: an investigation of failure criteria. J Biomech Eng 120:181-187

6. Baratz ME, Fu FH, Mengato R (1986) Meniscal tears: the effect of meniscectomy and of repair on intraarticular contact areas and stress in the human knee. A preliminary report. Am J Sports Med $14: 270-275$

7. Bhattacharyya T, Gale D, Dewire P, Totterman S, Gale ME, McLaughlin S, Einhorn TA, Felson DT (2003) The clinical importance of meniscal tears demonstrated by magnetic resonance imaging in osteoarthritis of the knee. J Bone Joint Surg Am 85A:4-9

8. Boursinos LA, Karachalios T, Poultsides L, Malizos KN (2009) Do steroids, conventional non-steroidal anti-inflammatory drugs and selective Cox-2 inhibitors adversely affect fracture healing? J Musculoskelet Neuronal Interact 9:44-52

9. Brandt KD, Radin EL, Dieppe PA, van de Putte L (2006) Yet more evidence that osteoarthritis is not a cartilage disease. Ann Rheum Dis 65:1261-1264

10. Brittberg M (2008) Autologous chondrocyte implantation-technique and long-term follow-up. Injury 39(Suppl 1):S40-S49

11. Brittberg M, Lindahl A, Nilsson A, Ohlsson C, Isaksson O, Peterson L (1994) Treatment of deep cartilage defects in the knee with autologous chondrocyte transplantation. N Engl J Med 331:889-895

12. Brucker PU, Braun S, Imhoff AB (2008) Mega-OATS techniqueautologous osteochondral transplantation as a salvage procedure for large osteochondral defects of the femoral condyle. Oper Orthop Traumatol 20:188-198

13. Burr DB, Radin EL (2003) Microfractures and microcracks in subchondral bone: are they relevant to osteoarthrosis? Rheum Dis Clin North Am 29:675-685

14. Clines GA (2009) Prospects for osteoprogenitor stem cells in fracture repair and osteoporosis. Curr Opin Organ Transplant (e-pub ahead of print)

15. Custers RJ, Dhert WJ, Saris DB, Verbout AJ, van Rijen MH, Mastbergen SC, Lafeber FP, Creemers LB (2009) Cartilage degeneration in the goat knee caused by treating localized cartilage defects with metal implants. Osteoarthritis Cartilage (e-pub ahead of print)

16. Custers RJ, Dhert WJ, van Rijen MH, Verbout AJ, Creemers LB, Saris DB (2007) Articular damage caused by metal plugs in a rabbit model for treatment of localized cartilage defects. Osteoarthritis Cartilage 15:937-945

17. Custers RJ, Saris DB, Dhert WJ, Verbout AJ, van Rijen MH, Mastbergen SC, Lafeber FP, Creemers LB (2009) Articular cartilage degeneration following the treatment of focal cartilage defects with ceramic metal implants and compared with microfracture. J Bone Joint Surg Am 91:900-910

18. Daftari TK, Whitesides TE Jr, Heller JG, Goodrich AC, McCarey BE, Hutton WC (1994) Nicotine on the revascularization of bone graft. An experimental study in rabbits. Spine 19:904-911 
19. Davies JE, Hosseii MM (2000) Histodynamics of endosseous wound healing. In: Davies JE (ed) Bone engineering. Em squared Inc, Toronto, pp 1-14

20. Dhollander AA, Huysse WC, Verdonk PC, Verstraete KL, Verdonk R, Verbruggen G, Almqvist KF (2009) MRI evaluation of a new scaffold-based allogenic chondrocyte implantation for cartilage repair. Eur J Radiol (e-pub ahead of print)

21. Dorotka R, Bindreiter U, Macfelda K, Windberger U, Nehrer S (2005) Marrow stimulation and chondrocyte transplantation using a collagen matrix for cartilage repair. Osteoarthritis Cartilage 13:655-664

22. Duarte PM, Nogueira Filho GR, Sallum EA, de Toledo S, Sallum AW, Nociti FH Jr (2001) The effect of an immunosuppressive therapy and its withdrawal on bone healing around titanium implants. A histometric study in rabbits. J Periodontol 72:13911397

23. Esteves JC, Aranega AM, Borrasca AG, Fattah CM, Garcia IR Jr (2008) Repair process of surgical defects filled with autogenous bone grafts in tibiae of diabetic rats. J Appl Oral Sci 16:316320

24. Garrett JC (1994) Fresh osteochondral allografts for treatment of articular defects in osteochondritis dissecans of the lateral femoral condyle in adults. Clin Orthop Relat Res 303:33-37

25. Ghazavi MT, Pritzker KP, Davis AM, Gross AE (1997) Fresh osteochondral allografts for post-traumatic osteochondral defects of the knee. J Bone Joint Surg Br 79:1008-1013

26. Gillogly SD (2003) Treatment of large full-thickness chondral defects of the knee with autologous chondrocyte implantation. Arthroscopy 19(Suppl 1):147-153

27. Gold GE, Bergman AG, Pauly JM, Lang P, Butts RK, Beaulieu CF, Hargreaves B, Frank L, Boutin RD, Macovski A, Resnick D (1998) Magnetic resonance imaging of knee cartilage repair. Top Magn Reson Imaging 9:377-392

28. Gudas R, Kalesinskas RJ, Kimtys V, Stankevicius E, Toliusis V, Bernotavicius G, Smailys A (2005) A prospective randomized clinical study of mosaic osteochondral autologous transplantation versus microfracture for the treatment of osteochondral defects in the knee joint in young athletes. Arthroscopy 21:1066-1075

29. Hangody L, Fules P (2003) Autologous osteochondral mosaicplasty for the treatment of full-thickness defects of weightbearing joints: ten years of experimental and clinical experience. J Bone Joint Surg Am 85A(Suppl 2):25-32

30. Harding AK, Aspenberg P, Kataoka M, Bylski D, Tagil M (2008) Manipulating the anabolic and catabolic response in bone graft remodeling: synergism by a combination of local BMP-7 and a single systemic dosis of zoledronate. J Orthop Res 26:1245-1249

31. Hasselbach C, Witzel U (2007) Klinik und Biomechanik des Knorpelersatzimplantates HemiCAP. In: Deutscher Kongress fuer Orthopaedie und Unfallchirurgie

32. Hunter DJ, Zhang YQ, Niu JB, Tu X, Amin S, Clancy M, Guermazi A, Grigorian M, Gale D, Felson DT (2006) The association of meniscal pathologic changes with cartilage loss in symptomatic knee osteoarthritis. Arthritis Rheum 54:795-801

33. Jakobsen RB, Engebretsen L, Slauterbeck JR (2005) An analysis of the quality of cartilage repair studies. J Bone Joint Surg Am 87:2232-2239

34. Jiang CC, Chiang H, Liao CJ, Lin YJ, Kuo TF, Shieh CS, Huang YY, Tuan RS (2007) Repair of porcine articular cartilage defect with a biphasic osteochondral composite. J Orthop Res 25:12771290

35. Johnson LL (2001) Arthroscopic abrasion arthroplasty: a review. Clin Orthop Relat Res 391:S306-S317

36. Jones DG, Peterson L (2007) Autologous chondrocyte implantation. Instr Course Lect 56:429-445

37. Judex S, Gupta S, Rubin C (2009) Regulation of mechanical signals in bone. Orthod Craniofac Res 12:94-104
38. Kirker-Head CA, Van Sickle DC, Ek SW, McCool JC (2006) Safety of, and biological and functional response to, a novel metallic implant for the management of focal full-thickness cartilage defects: preliminary assessment in an animal model out to 1 year. J Orthop Res 24:1095-1108

39. Knutsen G, Engebretsen L, Ludvigsen TC, Drogset JO, Grontvedt T, Solheim E, Strand T, Roberts S, Isaksen V, Johansen O (2004) Autologous chondrocyte implantation compared with microfracture in the knee. A randomized trial. J Bone Joint Surg Am 86A:455-464

40. Kon E, Delcogliano M, Filardo G, Altadonna G, Marcacci M (2009) Novel nano-composite multi-layered biomaterial for the treatment of multifocal degenerative cartilage lesions. Knee Surg Sports Traumatol Arthrosc 17:1312-1315

41. Kon E, Delcogliano M, Filardo G, Montaperto C, Marcacci M (2008) Second generation issues in cartilage repair. Sports Med Arthrosc 16:221-229

42. Kreuz PC, Steinwachs MR, Erggelet C, Krause SJ, Konrad G, Uhl M, Sudkamp N (2006) Results after microfracture of fullthickness chondral defects in different compartments in the knee. Osteoarthritis Cartilage 14:1119-1125

43. Lattermann C, Romine SE (2009) Osteochondral allografts: state of the art. Clin Sports Med 28:285-301

44. Lazarovici TS, Yahalom R, Taicher S, Elad S, Hardan I, Yarom N (2009) Bisphosphonate-related osteonecrosis of the jaws: a single-center study of 101 patients. J Oral Maxillofac Surg 67:850-855

45. Lee SJ, Aadalen KJ, Malaviya P, Lorenz EP, Hayden JK, Farr J, Kang RW, Cole BJ (2006) Tibiofemoral contact mechanics after serial medial meniscectomies in the human cadaveric knee. Am J Sports Med 34:1334-1344

46. Lo GH, Hunter DJ, Zhang Y, McLennan CE, Lavalley MP, Kiel DP, McLean RR, Genant HK, Guermazi A, Felson DT (2005) Bone marrow lesions in the knee are associated with increased local bone density. Arthritis Rheum 52:2814-2821

47. Lo GH, Niu J, McLennan CE, Kiel DP, McLean RR, Guermazi A, Genant HK, McAlindon TE, Hunter DJ (2008) Meniscal damage associated with increased local subchondral bone mineral density: a Framingham study. Osteoarthritis Cartilage 16:261267

48. Mach DB, Rogers SD, Sabino MC, Luger NM, Schwei MJ, Pomonis JD, Keyser CP, Clohisy DR, Adams DJ, O'Leary P, Mantyh PW (2002) Origins of skeletal pain: sensory and sympathetic innervation of the mouse femur. Neuroscience 113:155166

49. Magnussen RA, Dunn WR, Carey JL, Spindler KP (2008) Treatment of focal articular cartilage defects in the knee: a systematic review. Clin Orthop Relat Res 466:952-962

50. Marlovits S, Singer P, Zeller P, Mandl I, Haller J, Trattnig S (2006) Magnetic resonance observation of cartilage repair tissue (MOCART) for the evaluation of autologous chondrocyte transplantation: determination of interobserver variability and correlation to clinical outcome after 2 years. Eur J Radiol 57:16-23

51. McKinley TO, English DK, Bay BK (2003) Trabecular bone strain changes resulting from partial and complete meniscectomy. Clin Orthop Relat Res 407:259-267

52. McNickle AG, L'Heureux DR, Yanke AB, Cole BJ (2009) Outcomes of autologous chondrocyte implantation in a diverse patient population. Am J Sports Med 37:1344-1350

53. Minas T, Gomoll AH, Rosenberger R, Royce RO, Bryant T (2009) Increased failure rate of autologous chondrocyte implantation after previous treatment with marrow stimulation techniques. Am J Sports Med 37:902-908

54. Mithoefer K, McAdams TR, Scopp JM, Mandelbaum BR (2009) Emerging options for treatment of articular cartilage injury in the athlete. Clin Sports Med 28:25-40 
55. Mithoefer K, Williams RJ 3rd, Warren RF, Potter HG, Spock CR, Jones EC, Wickiewicz TL, Marx RG (2005) The microfracture technique for the treatment of articular cartilage lesions in the knee. A prospective cohort study. J Bone Joint Surg Am 87:1911-1920

56. Morshed S, Tornetta P 3rd, Bhandari M (2009) Analysis of observational studies: a guide to understanding statistical methods. J Bone Joint Surg Am 91(Suppl 3):50-60

57. Moyad TF, Minas T (2008) Opening wedge high tibial osteotomy: a novel technique for harvesting autograft bone. J Knee Surg 21:80-84

58. Nagura I, Fujioka H, Kokubu T, Makino T, Sumi Y, Kurosaka M (2007) Repair of osteochondral defects with a new porous synthetic polymer scaffold. J Bone Joint Surg Br 89:258-264

59. Niederauer GG, Slivka MA, Leatherbury NC, Korvick DL, Harroff HH, Ehler WC, Dunn CJ, Kieswetter K (2000) Evaluation of multiphase implants for repair of focal osteochondral defects in goats. Biomaterials 21:2561-2574

60. Odgaard A, Pedersen CM, Bentzen SM, Jorgensen J, Hvid I (1989) Density changes at the proximal tibia after medial meniscectomy. J Orthop Res 7:744-753

61. Paletta GA Jr, Manning T, Snell E, Parker R, Bergfeld J (1997) The effect of allograft meniscal replacement on intraarticular contact area and pressures in the human knee. A biomechanical study. Am J Sports Med 25:692-698

62. Petersen MM, Olsen C, Lauritzen JB, Lund B, Hede A (1996) Late changes in bone mineral density of the proximal tibia following total or partial medial meniscectomy. A randomized study. J Orthop Res 14:16-21

63. Peterson L, Minas T, Brittberg M, Lindahl A (2003) Treatment of osteochondritis dissecans of the knee with autologous chondrocyte transplantation: results at two to ten years. J Bone Joint Surg Am 85A(Suppl 2):17-24

64. Pridie E (1959) A method of resurfacing knee joints. J Bone Joint Surg Br 41:618-619

65. Radin EL, Rose RM (1986) Role of subchondral bone in the initiation and progression of cartilage damage. Clin Orthop Relat Res 213:34-40

66. Recht M, Bobic V, Burstein D, Disler D, Gold G, Gray M, Kramer J, Lang P, McCauley T, Winalski C (2001) Magnetic resonance imaging of articular cartilage. Clin Orthop Relat Res 391:S379-S396

67. Schagemann JC, Erggelet C, Chung HW, Lahm A, Kurz H, Mrosek EH (2009) Cell-laden and cell-free biopolymer hydrogel for the treatment of osteochondral defects in a sheep model. Tissue Eng Part A 15:75-82

68. Schlichting K, Schell H, Kleemann RU, Schill A, Weiler A, Duda GN, Epari DR (2008) Influence of scaffold stiffness on subchondral bone and subsequent cartilage regeneration in an ovine model of osteochondral defect healing. Am J Sports Med 36:2379-2391

69. Shirazi R, Shirazi-Adl A (2009) Computational biomechanics of articular cartilage of human knee joint: effect of osteochondral defects. J Biomech 42:2458-2465
70. Simon WH (1970) Scale effects in animal joints. I. Articular cartilage thickness and compressive stress. Arthritis Rheum 13:244-256

71. Steadman JR, Briggs KK, Rodrigo JJ, Kocher MS, Gill TJ, Rodkey WG (2003) Outcomes of microfracture for traumatic chondral defects of the knee: average 11-year follow-up. Arthroscopy 19:477-484

72. Steadman JR, Rodkey WG, Rodrigo JJ (2001) Microfracture: surgical technique and rehabilitation to treat chondral defects. Clin Orthop Relat Res 391:S362-S369

73. Sugita T, Kawamata T, Ohnuma M, Yoshizumi Y, Sato K (2001) Radial displacement of the medial meniscus in varus osteoarthritis of the knee. Clin Orthop Relat Res 387:171-177

74. Unay K, Poyanli O, Akan K, Guven M, Demircay C (2009) The relationship between bone marrow edema size and knee pain. Knee Surg Sports Traumatol Arthrosc 17:1298-1304

75. Vadher SP, Nayeb-Hashemi H, Canavan PK, Warner GM (2006) Finite element modeling following partial meniscectomy: effect of various size of resection. Conf Proc IEEE Eng Med Biol Soc 1:2098-2101

76. Verhagen R (2004) Thesis: Diagnostic guidelines for chronic ankle pain. 2004, Amsterdam

77. W-Dahl A, Toksvig-Larsen S (2007) No delayed bone healing in Swedish male oral snuffers operated on by the hemicallotasis technique: a cohort study of 175 patients. Acta Orthop 78:791794

78. Wasiak J, Clar C, Villanueva E (2006) Autologous cartilage implantation for full thickness articular cartilage defects of the knee. Cochrane Database Syst Rev 3:CD003323

79. White AP, Vaccaro AR, Hall JA, Whang PG, Friel BC, McKee MD (2007) Clinical applications of BMP-7/OP-1 in fractures, nonunions and spinal fusion. Int Orthop 31:735-741

80. Williams RJ, Gamradt SC (2008) Articular cartilage repair using a resorbable matrix scaffold. Instr Course Lect 57:563-571

81. Wilson W, van Rietbergen B, van Donkelaar CC, Huiskes R (2003) Pathways of load-induced cartilage damage causing cartilage degeneration in the knee after meniscectomy. J Biomech $36: 845-851$

82. Wise SK, Harvey RJ, Neal JG, Patel SJ, Frankel BM, Schlosser RJ (2009) Factors contributing to failure in endoscopic skull base defect repair. Am J Rhinol Allergy 23:185-191

83. Zengerink M, Struijs P, Tol J, van Dijk C (2009) Treatment of osteochondral lesions of the talus: systematic review. KSSTA (e-pub ahead of print)

84. Zielinska B, Donahue TL (2006) 3D finite element model of meniscectomy: changes in joint contact behavior. J Biomech Eng 128:115-123

85. Ziran BH, Hendi P, Smith WR, Westerheide K, Agudelo JF (2007) Osseous healing with a composite of allograft and demineralized bone matrix: adverse effects of smoking. Am J Orthop 36:207-209 